معوقات توظيف تقتيات التعليم التي تواجه معلمي صعويات التعلم بالمملكة العربية السعودية

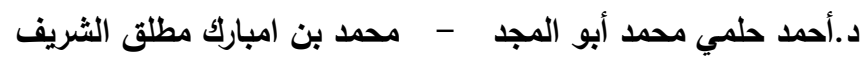

\title{
هموقات توظيف تقنيات التعليم التي تواجه هملهي صعوبات التعلم بالمملكة العربية السعودية
}

\author{
د.أهمد هلمي هممد أبو المهد \\ مدرس تكنولوجيا التعليم \\ كلية التربية النوعية - جامعة جنوب الوادي \\ هممد بن اهببارك هطلق الشريف \\ معلم صعويات التعلم بتعليم مكة
}


معوقات توظيف تقتيات التعليم التي تواجه معلمي صعويات التعلم بالمملكة العربية السعودية

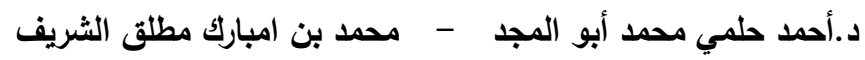




\section{هلفص البمث}

عنوان البـث : معوقات توظيف تقنيات التعليم التي تواجه معلمي صعوبات التعلم بالمرحلة الابتدائية بمدينة مكة المكرمة

هدفت البحث إلى التعرف على معوقات توظيف تقنيات التعليم التي تواجه معلمي صعوبات التعلم بالمرحلة الابتدائية بمدينة مكة المكرمة. عينة البحث: تكون من( 70) معلم وتمثلت، واستخدمت الاسنبانة كأداة للاراسة وهي مكونة من خمسة محاور ومكونة من ( 47) عبارة، وتراوح ثبات محاورها من ( 0.90) إلى ( 0.95)، وعرضت على ( 15) محكما واستخدمت في البحث الأساليب الإحصائية: التكرارات والنسبة المئوية والمتوسط الحسابي واختبار (ت)، واختبار مان وتتي(ي)، واختبار كروسال، والاتساق الداخلي للصدق، ومعامل ألفا كرونباخ للنبات.

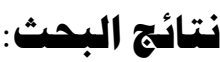

- أظهرث النتائج وجود معوقات توظيف تقنيات التعليم تواجه معلمي صعوبات التعلم

بالمرحلة الابتدائية بمدينة مكة المكرمة تشمل المعوقات ( بالمعلم، بالإدارة

$$
\text { المدرسية، بالمنهج). }
$$

- وجود فروق دالة إحصائيا بين منوسطات استجابات عينة البحث حول معوقات توظيف تقنيات التعليم التي تواجه معلمي صعوبات التعلم بالمرحلة الابتدائية حسب

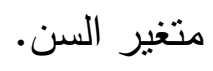

- عدم وجود فروق دالة إحصائيا بين متوسطات استجابات عينة البحث حول معوقات توظيف تقنيات التعليم التي تواجه معلمي صعوبات التعلم بالمرحلة الابتدائية حسب متغير المؤهل العلمي.

- عدم وجود فروق دالة إحصائيا بين متوسطات استجابات عينة البحث حول معوقات توظيف تقنيات التعليم التي تواجه معلمي صعوبات التعلم بالمرحلة

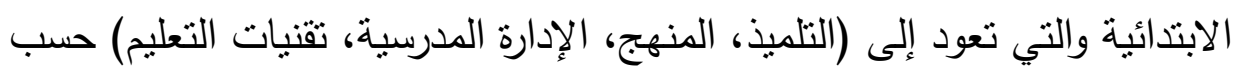
متغير الخبرة العلمية. 
معوقات توظيف تقتيات التعليم التي تواجه معلمي صعويات التعلم بالمملكة العربية السعودية

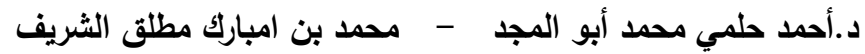

- وجود فروق دالة إحصائيا بين متوسطات استجابات عينة البحث حول معوقات توظيف تقنيات التعليم التي تواجه معلمي صعوبات التعلم بالمرحلة الابتذائية والتي تعود إلى (المعلم) حسب منغير الخبرة العلمية.

- وجود فروق دالة إحصائيا بين متوسطات استجابات عينة البحث حول معوقات توظيف تقنيات التعليم التي تواجه معلمي صعوبات التعلم بالمرحلة الابتدائية حسب متغير الدورات التدريبية.

التوصوصيات:

- ضرورة العمل على تذليل معوقات توظيف تقنيات التعليم التي تواجه معلمي صعوبات التعلم بالمرحلة الابتدائية.

- الاهتمام والتزكيز على معلمي صعوبات التعلم ذوو فئات السن الصغيرة لتنليل

$$
\text { المعوقات التي بواجهونها. }
$$

- مراعاة البرامج التي تقدم للارسين في الدبلوم العالي وأهمية تضمينه لموضوعات تخدم تقنيات التعليم.

- - الاهنمام بالمعلمين حديثي التخرج حيث هم الأكثر تعرضا للمعوقات. - - الاهتمام بعقد دورات تدريبية في مجال توظيف تقنيات التعليم.

\section{Abstract}


معوقات توظيف تقتيات التغليم التي تواجه معلمي صعويات التطلم بالملكة العربية السعودية

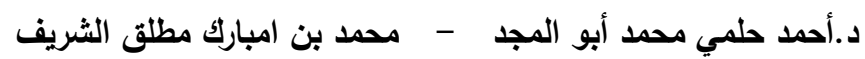

Title of the Study:"Obstacles To Recruit Teaching Technologies That Teachers Of Learning Difficulties Face At Elementary Stage In MakkahCity".

Objectives of the study: The study aimed to identify the obstacles to recruit teaching technologies that teachers of learning difficulties face at elementary stage in Makkah city. Procedures of the study:

The researcher used the descriptive methodology in this study, the study community consisted of(73) teacher and the study sample was (70) teacher, the questionnaire was used as a tool for the study, it has five axes that consisted of (47) statement, stability of the axes ranged from (0.90) to (0.95), presented to (15) arbitrator, statistical methods as repetitions, percentages, arithmetic mean and the T-test, Mann-Whitney test (I), Krosal test, internal consistency of reliability, alpha Cronbach's coefficient for validity.

\section{Results of the study:}

- The results showed that there are obstacles to recruit teaching technologies that teachers of learning difficulties facing at elementary stage in Makkah include to (teacher, curriculum, school administration)?

- There are significant differences between the mean responses of the sample about the obstacles to recruit teaching technologies that teachers of learning difficulties face at elementary stage according to the variable of age.

- There aren't statistically significant differences between the mean responses of the sample about the obstacles to recruit teaching technologies that teachers learning difficulties face at the elementary stage according to the variable of scientific qualification.

- There aren't statistically significant differences between the mean responses of the sample about the obstacles to recruit 
معوقات توظيف تقتيات التعليم التي تواجه معلمي صعويات التعلم بالمملكة العربية السعودية

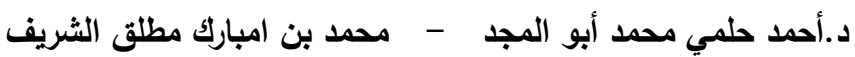

teaching technologies that teachers of learning difficulties face at elementary stage that due to (student, curriculum, school administration, teaching technologies) according to the variable of scientific experience.

- There are statistically significant differences between the mean responses of the sample about the obstacles to recruit teaching technologies that teachers of learning difficulties face at elementary stage that due to (teacher) according to the variable of scientific experience.

- There are statistically significant differences between the mean responses of the sample about the obstacles to recruit teaching technologies that teachers of learning difficulties face at elementary stage according to the variable of training courses.

Recommendations:

- The urgent need to overcome the obstacles to recruit teaching technologies that teachers of learning difficulties face at elementary stage.

- Paying attention and focus on the teachers of learning difficulties with law age groups to overcome the obstacles they face.

- Considering the programs that are presented for higher diploma students and the importance of including topics serving learning technologies.

- Caring about current graduated teachers as they are most facing these obstacles.

- Caring about holding of training courses at the field of education technologies recruitment 
يشهد العالم الآن العديد من التطورات المتلاحقة والمتسارعة في مختلف مجالات التطور العلمي والتقني مما أدى إلى ظهور ثورة كبيرة في التقنية وتطبيقاتها في جميع مجالات الحياة بصفة عامة والمجال التعليمي بصفة خاصة. والنظام التعليمي في مجتمعاتتا العربية يحتاج إلى مواكبة هذا التطور الذي يفرض علينا العمل على إعداد جيل قادر على تحقيق التتمية الدائمة في ظل المتغيرات المستمرة التي نعيش فيها.بحيث تشمل كافة عناصره وذللك لتحقيق الغايات المرجوة منه والتي تتفق مع منطلبات العصر الذي نعيش فيه، يعتبر للمعلم أهمية كبرى في العملية التربوية إذ يوجه التلاميذ ويرشدهم ويهيئ الفرص والظروف اللازمة لنموهم بما لديه من مهارة وقدرة على إثارة رغبة التلاميذ في التعليم من أجل تحقيق الأهداف التربوية بكل الطرق الإيجابية التي تؤدي إلى نتائج طيبة. - مين.

وفي هذا الصدد تؤكد جمعية الأطفال غير العاديين(2000,CEC) على أن معلمي التربية الخاصة يجب أن تتوفر لديهم المهارة في استخدام التقنيات التعليمية الخاصة، و القدرة على توفير بيئة تعليمية هادفة تسهم في بناء اتجاهات إيجابية نحو استخدام

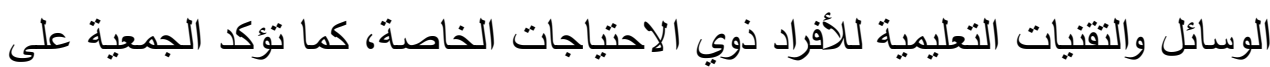
أن يقوم المعلمون بمساعدة التلاميذ على استخدام وسائل التواصل المختلفة التي تسهم في إدماج تللك الفئة بالمجتمع الخارجي. ويذكر (فتح الله، 2012م، ص5) أن استخدام التقنية في العملية التعليمية في

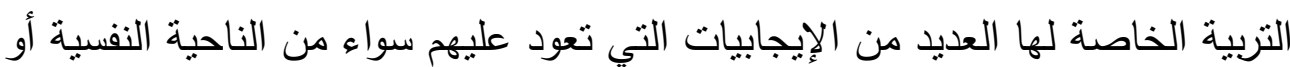
الأكاديمية أو الاجتماعية أو الاقتصادية. فاستخدام التقنيات التعليمية كالحاسب الآلي مثناً له دور كبير في خفض التوتر والانفعالات لدى التلاميذ ذوي صعوبات التعلم، وبذلك يستخدم كثير من المعلمين هذه الوسيلة كمعزز إيجابي أو سلبي في تعديل سلوك طلاب ذوي صعوبات التعلم. ويؤكد(الحازمي، 1430هـ،صو4) في دراسته على أن استخدام الكمبيونز من 
التقنيات التربوية الحديثة التي أثنتت فعاليتها في تعليم الأطفال المعاقين عقلياً ومقابلة الكثير من احتياجاتهم التربوية الخاصة، وكذللك يؤكد على فعالية الاستراتيجيات التدريسية التي تعتمد على برامج الكمبيونز في إكساب المعاق الكثير من المهارات

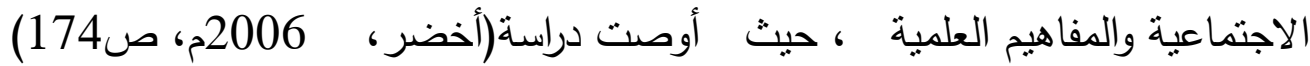
بضرورة توفير أجهزة الحاسب الآلي في معاهد وبرامج الأمل بالمملكة العربية السعودية وحيث أثارت نتائج الدراسة زيادة فاعلية استخدام الحاسب الآلي كوسيلة تعليمية في جميع المناهج، وأيضا العمل على إزالة المعوقات التي تحد من استخدام الحاسب الآلي في التدريس ومحو أمية المعلمين والمشرفين في هذا المجال. ويشير (المغلوث، 1419 هـ، ص 20) إلى أن المملكة العربية السعودية تتطلق أساساً من مبادئ الثريعة الإسلامية التي تؤكد على حقوق الإنسان في التعليم والرعاية

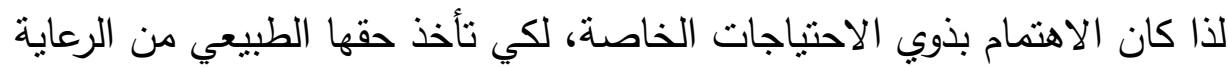

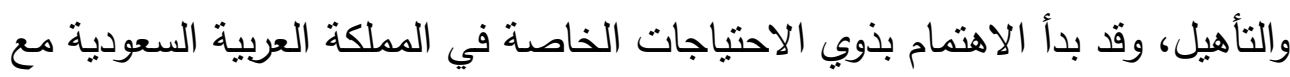
بداية التخطيط لبرامج التتمية الاجتماعية والاقتصادية. ويؤكد (العزة، 2002م، ص414) أن صعوبات التعلم عبارة عن اضطراب في أحد الجوانب أو أكثر من الوظائف العقلية أو النفسية التي تشمل الذاكرة والإدراك والانتباه والتخيل وحل المشكلات وفهم استخدام اللغة والتعبير بالكلام والكتابة، وتؤدي إلى عدم القدرة على الانتباه والتقكر والنطق والقراءة والكتابة والقيام بالعمليات الحسابية، وأن الاضطراب لا يكون ناتجا عن وجود إعاقات ظاهرة عند الفرد. ويشير (الريموني، 2008م، ص14) في هذا الصدد أن صعوبات التعلم هي : الحالة التي يظهر صاحبها مشكلة أو أكثر في الجوانب الآتية: القدرة على استخدام اللغة وفهمها، والقدرة

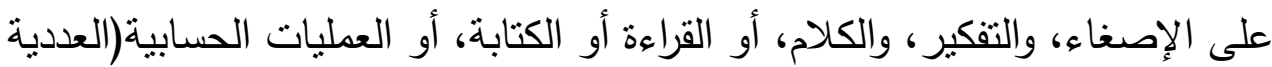
البسيطة). ويعود السبب في ذلك إلى صعوبات في عمليات الإدراك، وإلى إصابات الدماغ، أو صعوبات في القراءة، أو فقدان القدرة على الكلام، أي أن الصعوبة في في الصدي التعلم لا تعود إلى إعاقة سمعية، أو بصرية، أو حركية، أو انفعالية. 
في ضوء ما ورد عن (وزارة العمل والثئون الاجتماعية، 2003م، صة18-31) أن المملكة العربية السعودية قد وضعت أهداف سياستها نحو ذوي الاحتياجات الخاصة والتي تسعى إلى تزويدهم بالقدر المناسب من المعرفة، والثقافة من مختلف الروافد بقدر ما تسمح به ظروف كل فئة من فئات ذوي الاحتياجات الخاصة. بالرغم مما أكدته القواعد التتظيمية للتزبية الخاصة( 1422هـ)، المادة الثامنة والتسعون بضرورة "أن تقوم المعاهد وبرامج التربية الخاصة بالمدارس العادية بتوظيف التقنيات وبرامج الحاسب الآلي للأغراض التعليمية وتتظيم الأعمال وتوثثي البيانات والمعلومات ونتائج التقويم".حيث استشعرت الأمانة العامة للتربية الخاصة أهمية استخدام التقنيات التعليمية وتوظيفها لخدمة العملية التربوية لذوي صعوبات التعلم، إلا أن الواقع ومن خلال معايشة الباحث ين، وجد أن التطبيق العملي لهذا الأمر لا يتم بالثكل المطلوب، ومن هنا استشعر الباحثين بمشكلة الدراسة وبأن هناك معوقات تحول دون توظيف المعلمين للتقنيات التعليمية بشكل بؤدي إلى استفادة الطلاب منها. مما سبق يمكن تحديد مشكلة البحث في العبارة التالية( ما معوقات توظيف تقتيات التعليم التي تواجه معلمي صعوبات التعلم بمدينة مكة المكرمة بالمملكة العربية (السعودية)

$$
\text { تتمثل أسئلة البحثة البحث: في السؤال الرئيس التالي: }
$$

ما معوقات توظيف تقنيات التعليم التي تواجه معلمي صعوبات لتئي التعلم بالمرحلة 
معوقات توظيف تقتيات التعليم التي تواجه معلمي صعويات التعلم بالمملكة العربية السعودية

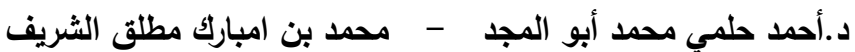

الابتدائية بمدنية مكة المكرمة؟ ويتفرع من هذا السؤال الأسئلة الفرعية التالية: I ما معوقات توظيف تقنيات التعليم التي تواجه معلمي صعوبات التعلم الخاصة بالمعلم؟.

r ما معوقات توظيف تقنيات التعليم التي تواجه معلمي صعوبات التعلم الخاصة بالإدارة المدرسية؟

3- ما معوقات توظيف تقنيات التعليم التي تواجه معلمي صعوبات التعلم الخاصة بالمنهج؟.

\section{تمثلت أهداف الدرافة البمثة:}

ا لالتعرف على معوقات توظيف تقنيات التعليم التي تواجه معلمي صعوبات الخاصة بالمعلم. r التعرف على معوقات توظيف تقنيات التعليم التي تواجه الإدارة المدرسية. ץ التعرف على معوقات توظيف تقنيات التعليم التي تواجه المنهج. تنبع أهمية الدر اسةة مما يلي: أهمث:

ا تـحاول إلقاء الضوء على المعوقات التي تحد من توظيف تقنيات التعليم التي تواجه معلمي صعوبات التعلم في تدريس التلاميذ ذوي صعوبات التعلم، مما يسهم في اتخاذ الإجراءات التي تعمل على التخلب على هذه المعوقات والاستفادة من إمكانيات تقنيات التعليم في تطوير العملية التعليمية. r - فتح المجال أمام الباحثنين لإجراء المزيد من الدراسات حول معلمي التلاميذ ذوي • صعوبات التعلم

r -قد تستقيد الجهات المسئولة عن تعليم ذوي صعوبات التعلم من نتائج هذه الدراسة الميدانية التي ستقدم بإذن الهه تصورًا واضحًا مبني على أسس علمية عن عند أبرز معوقات توظيف تقنيات التعليم التي تواجه معلمي تلاميذ صعوبات التعلم، والتي تحول دون استخدامهم للتقنيات التعليمية بشكل فعال. 
معوقات توظيف تقتيات التعليم التي تواجه معلمي صعويات التعلم بالمملكة العربية السعودية

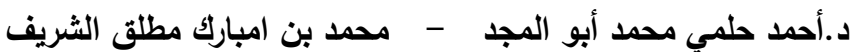

$$
\text { تتمثل حدود الدراسة في الآتي: }
$$

ا الحدود الموضوعية: معوقات توظيف تقنيات التعليم بالمرحلة الابتدائية بمدينة مكة

$$
\text { المكرمة. }
$$

r † الحدود البشرية: معلمي ومشرفي طلاب صعوبات التعلم بالمرحلة الابتدائية. ب الحدود المكانية: مدينة مكة المكرمة- المملكة العربية السعودية. ع - الحدود الزمانية: الفصل الدراسي الثاني من العام 1433-1434 هـ.

اعتمد البحث على المنهج الوصف الذي يعتمد على دراسة الظاهرة كما توجد في الواقع ويهنم بوصفها وصفاً دقيقاً، ويعبر عنها تعبيراً كيفياً أو كمياً. تكون عينة البحث الحالي من معلمي صعوبات التعلم بالمرحلة الابتدائية بمدينة مكة المكرمة، والبالغ عددهم ( 70) معلما و مشرفا، وقد تم التطبيق على كامل أفراد مجتمع البحث.

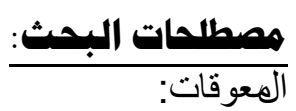

وتعرف إجرائيا في نطاق هذه الدراسة: جميع العوامل التي تؤثز بشكل سلبي

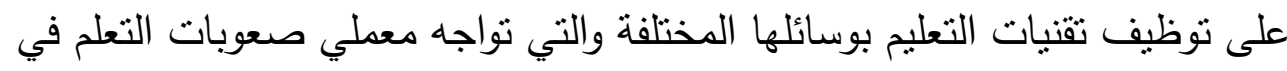
مناهج طلاب صعوبات التعلم، مما يقلل من الاستفادة بإمكانياتها. توظيف: يعرف( الغامدي، 2008م، ص 5) التوظيف بأنه:" القدرة على الاستخدام".

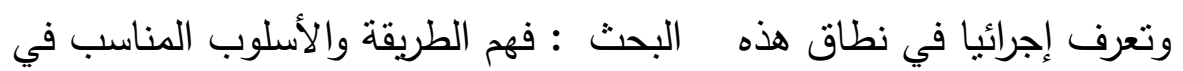

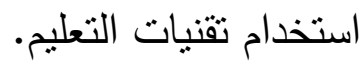

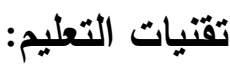
يعرف (سرايا، 2007م، ص38) تقنيات التعليم بأنها:" العلم الذي يبحث في

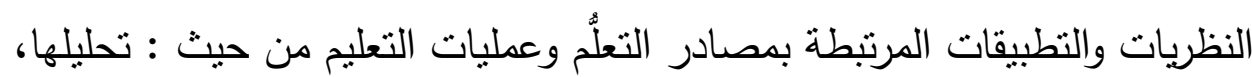
تصميمها، تطويرها، تتفيذها، إدارتها، تقويمها". 
معوقات توظيف تقتيات التعليم التي تواجه معلمي صعويات التعلم بالمملكة العربية السعودية

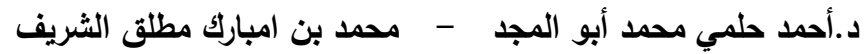

أما (سالم، 2010م، ص289) فيعرف تقنيات التعليم بأنها :"علم يبحث في

النظرية والتطبيق الخاصة بتصميم العمليات والمصادر وتطويرها، واستخدامها، وإدارتها، وتقويمها من أجل التعلم

وتعرف إجرائيا في نطاق هذه الدراسة: " أنها كل أداة أو وسيلة معقدة أ و غ غير

معقدة يستخدمها معلمو ا صعوبات التعلم بهدف شرح وتسهيل المادة التعليمية للتلاميذ ذوي صعوبات التعلم". توظيف تقنيات التعليم:

تعرف تقنيات التعليم إجرائيا في نطاق البحث بأنها؛ فهم واستخدام الطريقة التي يتعلم بها طلاب ذوي صعوبات التعلم وكيفية تصميم والاستفادة من تقنيات التعليم التي يستخدمها معلمي صعوبات التعلم لتسهيل عملية التعلم لدى الطلاب. صعوبات التعلم:

يعرفها (الريموني، 2008م، ص14) بأنها:" الحالة التي يظهر صاحبها مشكلة

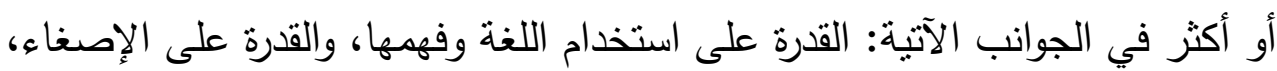
والتفكير، والكلام، أو القراءة أو الكتابة، أو العمليات الحسابية (العددية البسيطة).

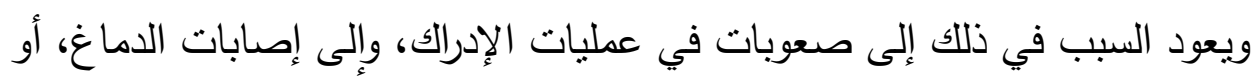

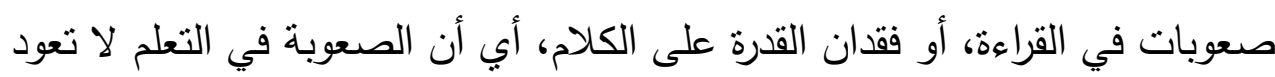
إلى إعاقة سمعية، أو بصرية، أو حركية، أو انفعالية".

وتعرف إجرائيا في نطاق هذه البحث: الحالة التي تظهر على بعض من الطلاب

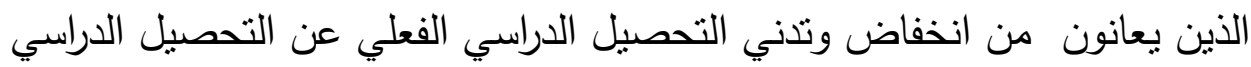
المتوقع منهم. الإطار النظري: أولا: تقتيات التعليم: مفهوم تقتيات التعليم: - من تزايد الاهتمام بوسائل وتقنيات التعليم من خلا العقود الأخيرة، نتيجة لما أسفرت 
معوقات توظيف تقتيات التعليم التي تواجه معلمي صعويات التعلم بالمملكة العربية السعودية

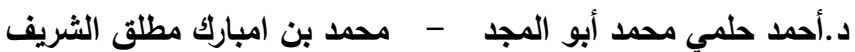

عنه البحوث والدراسات التربوية من جهة ولما حدث من تطورات علمية وتقنية متسارعة من جهة أخرى، أفضت نهاية المطاف إلى تطور أساليب التعليم باستخدام وسائل وتقنيات التعليم في كافة جوانب العملية التعليمية. ظهر هناك العديد من المسميات لوسائل الاتصال التعليمية وكما يذكر (الدعيلج، 1431هـ، ص 43) درج المربون على استعمال تسميات متعددة لوسائل الاتصال التعليمية منل: وسائل الإيضاح، أو الوسائل المعينة، أو الوسائل البصرية، أو معينات التدريس، أو الوسائل السمعية البصرية، أو الوسائل التعليمية، أو تقنيات التعليم. ويوضح(عطار وكنسارة،2008م، ص28،، 82) استعمل مصطلح تكنولوجيا، والذي

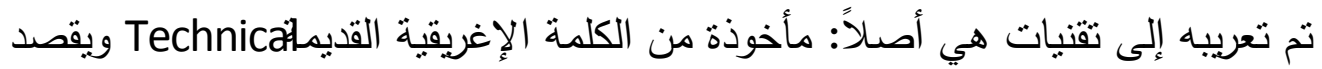
بها معالجة موضوعاً أو عملاً معالجة منظمةؤن كلمة تكنولوجيا هي الترجمة الأوروبية للكلمة العربية الأصل(تقني) التي تعود إلى رجل عربي يجيد فن الرماية بالرمح والنبل بمهارات عالية مما سمح المجال إلى إطلاق مصطلح رجل تقني لكل من يبدع في

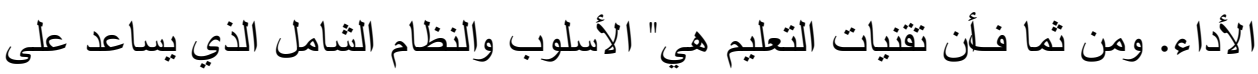
تتظيم وتقويم وتحسين العملية التعليمية". ويرى (سرايا وسالم، 2003م، ص2803) بأن التقنيات في مجال التعليم تعني" مجموعة التقنيات التفاعلية الحديثة التي تسمح بتفريد وإثراء المواقف التعليمية من خلال تغذيتها بعدة مصادر وبدائل متباينة، تشكل معاً وحدة متكاملة تهدف إلى تحقيق تعلم مثالي يتسم بقدر كبير من الفاعلية والكفاءة والإتقان" ويشير (سويدان والجزار ، 2007م، ص15) بأن تقنيات التعليم هي" عملية مركبة منكاملة تتضمن الأفراد والأساليب والأفكار والأجهزة وتتظيمها لتحليل وتصميم وتتفيذ وتقويم الحلول للمشكلات

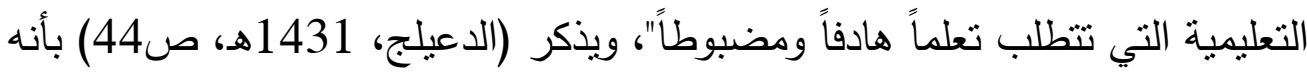
يقصد بالتقنية: "تطبيقات العلم لحل المشاكل العلمية، أب معالجة النظريات والحقائق العلمية والقوانين بطريقة منظمة شاملة، وتتم هذه المعالجة على أساس الاستفادة منها في الحياة العامة". 
ويضيف (ثمي وإسماعيل، 2008م، ص15) بأن تقنيات التعليم هي" عملية منهجية منظمة في تصميم عملية التعليم، والتعلم، وتتفيذها وتقويمها، في ضوء أهداف محددة تقوم أساساً على نتائج البحوث في مجالات المعرفة المختلفة، وتشتخدم جميع الموارد المتاحة البشرية، وغير البشرية، للوصول إلى تعلم أكثر فاعلية وكفاية".

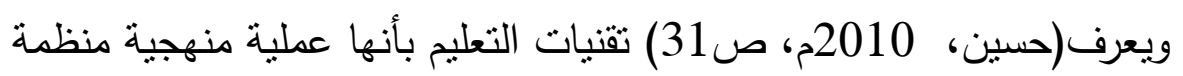

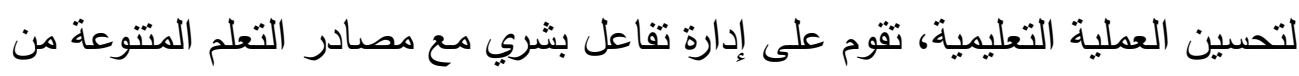

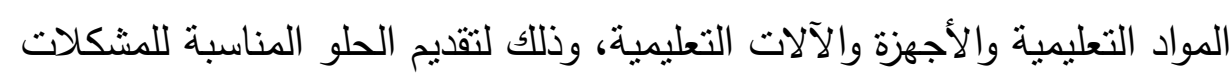
التعليمية وتحقيق الأهداف المحددة.

ويؤكد (الحيلة، 2010م، ص242) بأن التقنيات التعليمية هي" منحى نظامي

لتصميم العملية التعليمية وتتفيذها وتقويمها ككل، تبعا لأهداف محددة نابعة من نتائج الأبحاث في مجال التعليم، والاتصال البشري، ومستخدمة الموارد البشرية وغير البشرية من أجل إكساب التعليم مزيدا من الفاعلية". وبناء على ما سبق يتضح أن التقنيات التعليمية تعني أكثر من مجرد استخدام الأجهزة والآلات، فهي طريقة في التفكير فضلا على أنها منهج في العمل، وأسلوب في نئي حل المشكلات يعتمد على إتباع مخطط وأسلوب منهجيين. ويمكن أن تعرف على أنها:

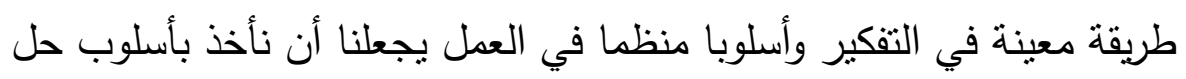
المشكلات التي تعتزرضنا مع الاستعانة بما يتاح من الوسائل وبنتائج البحوث التربوية في تخطيط إستراتيجية للعمل تحقق تقديم الحلول المناسبة لهذه المشكلات. معوقات توظيف تقنيات التعليم لتلاميذ ذوي صعوبات التعلم: على الرغم من النجاحات التي تحققها التقنيات التعليمية في العملية التعليمية والدور الكبير لها في عملية تدريس وخاصة تدريس تلاميذ صعوبات التعلم إلا أن المعلم كثيراً ما تعترضه بعض المعوقات عند استخدامه لهذه التقنيات في التدريس.

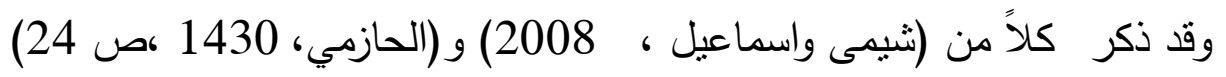
و (الفيفي، 1433هـ، ص 39) و (اللقماني، 2011م، ص 71) العديد من المعوقات 
معوقات توظيف تقتيات التعليم التي تواجه معلمي صعويات التعلم بالمملكة العربية السعودية

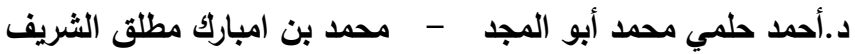

منها:

عدم توافر جميع تقنيات التعليم اللازمة للمواد التي يحتاجها تلاميذ صعوبات

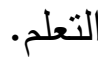
عدم توفر الظروف الملائمة لاستخدام الثقنيات التعليمية. صعوبة الحصول على تقنيات التعليم.

عدم التشجيع على صناعة التقنيات التعليمية باستخدام مصادر البيئة المحلية. عدم معرفة كثير من معلمي صعوبات التعلم بكيفية تشغيل وسائل وتقنيات التعليم لدى تلامبذ صعوبات التعلم. ارتفاع ثمن تكاليف بعض التقنيات التعليمية. عدم توفر المعلمين المدربين التدريب الملائم على استخدام تقنيات التعليم في تدريس تلاميذ صعوبات التعلم وخاصة في مجال تشغيل الأجهزة. كثرة الأعباء الملقاة على عاتق المعلم وازدحام الجدول الدراسي الخاص بهر. عدم إيمان بعض معلمي صعوبات التعلم بالقيمة التعليمية لتقنيات التعليم. عدم قناعة بعض مديري المدارس بأهمية توظيف تقنيات التعليم في العملية

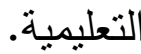
عدم التخطيط الجيد من قبل الإدارة المدرسية لتبني تقنيات التعليم الحديثة في العملية التعليمية. قصور التمويل والدعم اللازم من الإدارة المدرسية لتأسيس قاعد لتقنيات التعليم الحديثة في العملية التعليمية.

\section{ثانياً: صعوبات التعلم: هفهوم صعوبات التعلم:}

ظهر مفهوم صعوبات التعلم ولم يزل به العديد من الآراء، لأن فئات صعوبات التعلم متعددة؛ ونتيجة لاهتمام العديد من الباحثين في مجال التربية وعلم النفس بدراسة

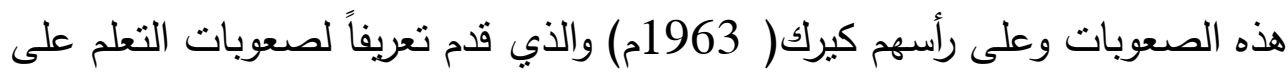


أنه يعني اضطرابات في واحدة أو أكثر من العمليات الأساسية المرتبطة بالحديث أو

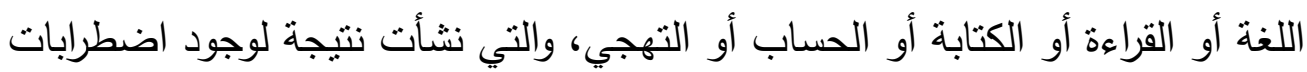
وظيفية في المخ أو اضطرابات سلوكية أو انفعالية، وليس لأي نتيجة من التأخر العقلي

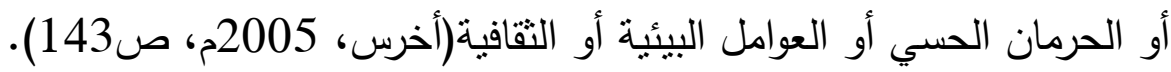

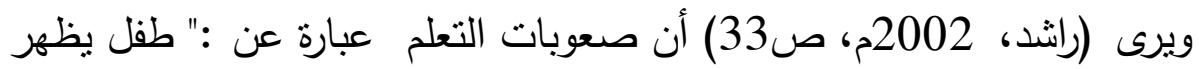
عليه بطء في المهارات الأكاديمية والحركية، وهو قادر على التحصيل والنجاح الأكاديمي، ولكن بمعدل أبطأ من الأطفال العاديين".

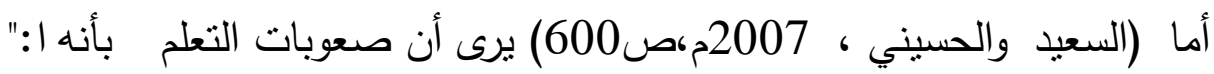

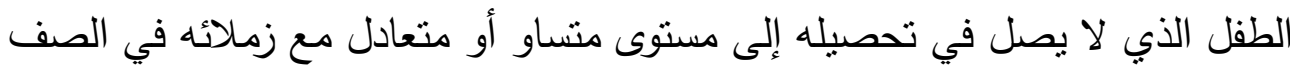
نفسه، وذللك في واحدة أو أكثر من الخبرات التعليمية المعدة لقدرات هذا الطفل وعمره".

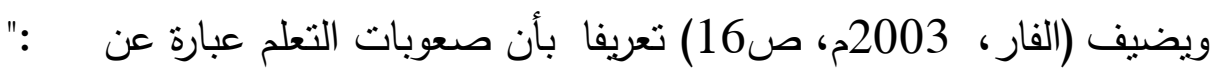
اضطرابات نفسية عصبية في التعلم وتحدث في أي سن، وتتتج عن انحرافات في بان

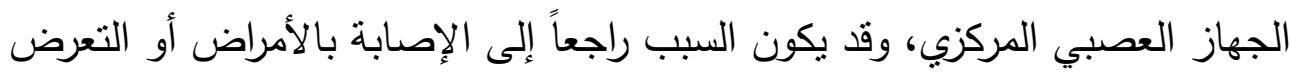

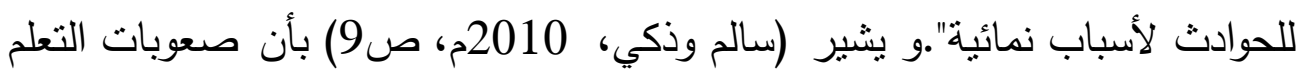

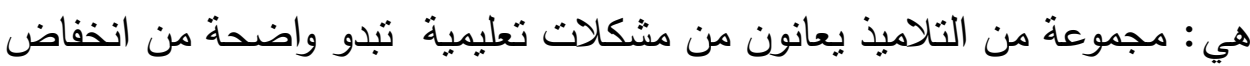
مستوى تحصيلهم الفعلي عن المتوقع منهم، على الرغم من تمتعهم بكل ما يتمتع به ماهيه

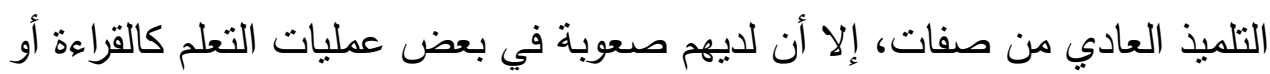
الحساب أو الفهم ويستبعد من هؤلاء المعوقون والمتخلفون عقليا.

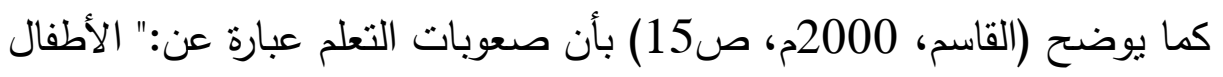
الذين يعانون من قصور في واحدة أو أكثز من العملية النفسية الأساسية التي تتطلب بأب فهم أو استخدام اللغة المكتوبة والمنطوقة، ويظهر هذا القصور ي نقص القدرة على

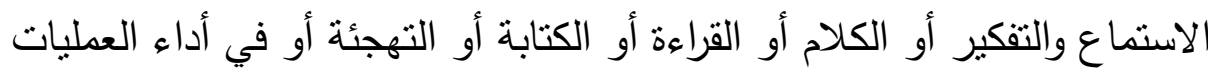
الحسابية، ويرجع هذا القصور إلى إعاقة في الإدراك أو إلى إصابة في المخ أو إلى الى الخلل الوظيفي الدماغي البسيط أو إلى عسر القراءة أو حبسه الكلام الإنمائية . ولا إلا 
يجوز أن تكون صعوبات العلم هذه ناتجة عن إعاقة بصرية أو سمعية أو حركية أو

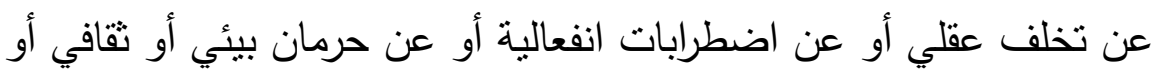

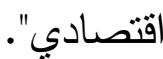

ومن خلال ما سبق يتضح أن هناك خصائص لصعوبات التعلم يمكن تلخيصها فيما يلي: انحراف في القدرات لدى الفرد في إطار نموه الذاتي. صعوبات التعلم تعد من الإعاقات المستقلة عن أية إعاقات أخرى. صعوبة التعلم غير ناتجة عن أية نوع من الإعاقات. ممكن أن تكون صعوبة التعلم تعليمية أو نفسية. أفراد صعوبات التعلم ليست لديهم مشكلة في الإنجاز أو الأداء. أفراد صعوبات التعلم موجودون في جميع المراحل العمرية وفي مختلف المستويات

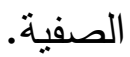

المجال التزبوي والانفعالي والاجتماعي غير مستثنى من هذه الصعوبات. قد تكون مصاحبة لأي إعاقة أخرى ومن المدكن وجودها لدى الموهوبين. أن تكون ذات صفة سلوكية مثل النطق والتفكير وتكوين المفاهيم.

هناك العديد من الأسباب التي تطرق إلبها المختصين في هذا المجال حيث أنه لا يوجد اتفاق في جميع الأسباب ولكن هي أسباب تختلف نظرا للجهة التي ينظر

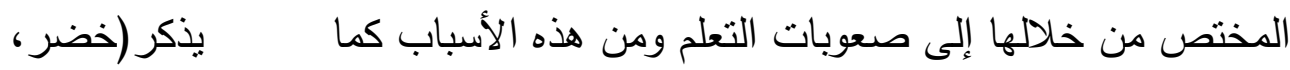
2005م، ص31) إلى أنه نتأثز عملية التعلم كغيرها من مظاهر السلوك والبناء النفسي لهني والثخصية والصحة، بالعديد من العوامل الجسمية والفردية والنفس اجتماعية، مثل إصابة المخ أو الاضطرابات الانفعالية أو نقص في الخبرة وتتمثل عوامل صعوبات

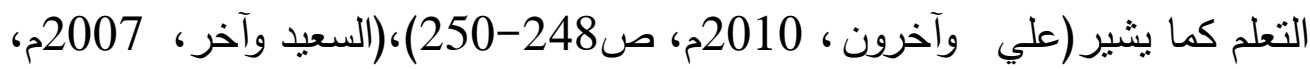
ص607-611) ،( الفار، 2003م، ص 40-41) ، (أخرس، 2005م، ص147- 
148) ،(القاسم، 2000م، ص280-40) و (القرني، 2008م، ص21) منها: أسباب عضوية وبيولوجية: ومنها إصابة الدماغ أو الخلل الدماغي الوظيفي واني البسيط، أو الأخطاء في نمو المخ لدى الجنين، ويقصد به النمو غير الطبيعي للمخ؛ نتيجة طول فترة الحمل، أو لأسباب أخرى؛ مما يؤدي إلى تغيرات في طريقة تكوين الخلايا العصبية، وطريقة ترابطها، ويكون المخ في هذه الحالة حساسا

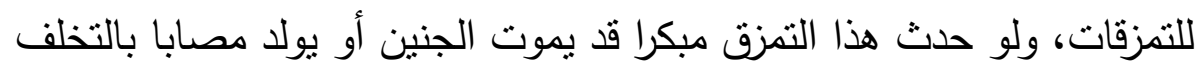

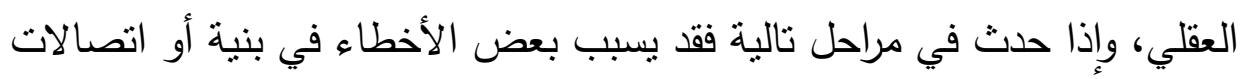
الخلية ويعتقد بعض العلماء أن هذه الأخطاء قد نظهر لاحقا في شكل صعوبات تعلم. أسباب جينية: وقد أشلات بعض الدراسات إلى انتشار صعوبات التعلم في عائلات معينة، وفي الواقع إن توريث صعوبات التعلم بعينها أمر غير وارد بالمرة، وبعيد الاحتمال، وإنا قد يرث الطفل من والديه الاختلال الوظيفي، الذي يؤدي إلى بلى بلى

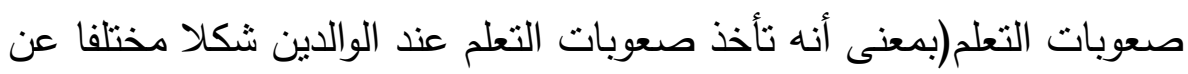
الطفل) فالوالد الذي يعاني من اضطرابات الكتابة، قد يكون له طفل يعاني اضطرابات اللغة التعبيرية وهكذا). إلا أنه في بعض الأحيان قد تتشأ صعوبات التعلم من بيئة الأسرة؛ لأن الآباء الذين يعانون اضطرابات في اللغة التعبيرية غالبا

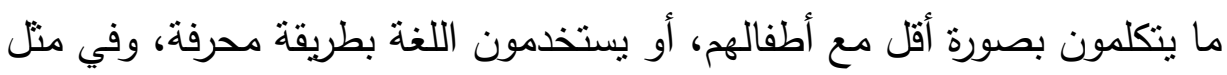
هذه الحالات يفتقد هذا الطفل القدوة الجيدة التي يكسب منها اللغة؛ مما يحدث لديه نوعا من صعوبات التعلم.

عوامل بيئية: ومنها المشكلات التي قد يتعرض لها الجنين في أثناء الحمل أو الولادة منل الأمراض التي تصيب الأم أو تدخين الأم في أثناء الحمل، أو تعاطيها المخدرات أو العقاقير أو انقطاع الأكسجين عن الطفل في أثثاء الولادة بصورة مؤقتة مما يؤدي إلى تعطل وظائف المخ، أو تعرض الطفل للمواد الكيميائية. وقد

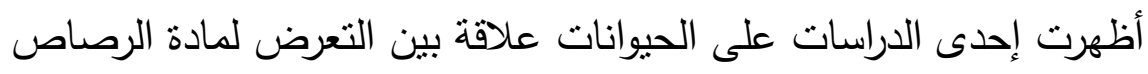


وصعوبات التعلم، حيث وجد أن الفئران الذي تعرضوا للرصاص، قد حدثت عندهم تغيرات في موجات المخ أبطأت قدرتهم على التعلم. ومن هذه العوامل البيئية أيضا

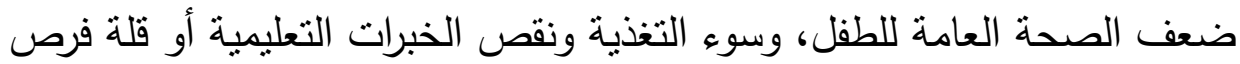
التدريب بالإضافة إلى إجبار الطفل على الكتابة باليد اليمنى. عوامل كيميائية حيوية: قد ترتبط صعوبات التعلم بقصور التوازن الكيميائي الحيوي في الجسم حيث من المفترض أن جسم الإنسان يحتوبي على نسب محددة من

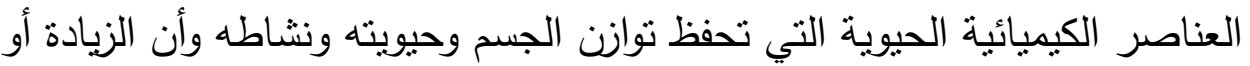
النقص في معدل هذه العناصر يؤثز على خلايا المخ فيما يعرف بالخلل الوظيفي المخي البسيط، ومن أمنلة قصور النوازن الكيميائي الحيوي ترسب حمض البروفيك يكي الفينالين الذي يعتبر واحدا من أسباب التخلف العقلي، ويرجع قصور التوازن الكيميائي الحيوي في الجسم إلى الطبيعة ونوعية الأطعمة التي يتتاولها الطفل

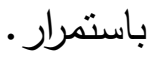

ويؤكد(الصالح، 2003م) في دراسته الميدانية أن من أسباب صعوبات التعلم ما يلى :

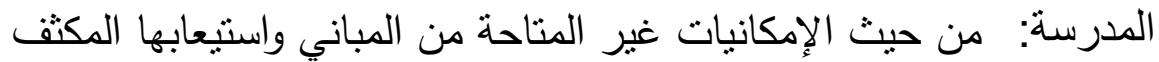
للطلاب وعدم إتاحتها الفرصة لممارسة الأنشطة، وعدم توفريها الوسائل التعليمية، والمناهج من حيث مضمونها غير العلمي الذي لا يراعي التطورات التكنولوجية ولا برتبط بمتطلبات البيئة، وعدم مراعاته مستويات الطلاب العمرية والفروق الفردية بينهم. المعلم: من الممكن أن يكون المعلم معوقا لعلمية التعلم، ومن ثم يكون أحد الأسباب التي تؤدي إلى صعوبات التعلم عندما لا يقوم بمهته بشكل جيد، وعدم استخدامه لطرق تدريس مناسبة وحديثة وغير تقليدية، وكذلك عدم إلمامه بطرق التقويم التربوي، إضافة إلى ضعف إعداده المهني قبل وأثناء الخدمة، وعدم مراعاته للفروق 
المتعلم: في حال كونه يعاني من مشكلات صحية كضعف البصر أو السمع أو صعوبات النطق، وعدم وجود اهتمامات للتعلم، والخوف من المدرسة، وانخفاض

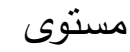

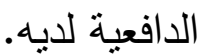

الأسرة: من خلال حرمان الطفل من المشاعر العاطفية، وعدم مراقبتها ومتابعتها لأبنائها، مع عدم توفر منطلباتهم الدراسية والمناخ المناسب للدراسة في المنزل وعدم

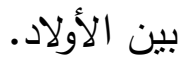

ومن خلال ما سبق يتضح أن هناك أسباب تم إغفالها وتعد من الأسباب الحقيقة

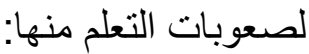
تتظيم النسل والتباعد الزمني بين الولادات المتعاقبة. عدد أطفال العائلة، من حيث الكثرة أو القلة. كثرة التتقل والسفر وعدم الاستقرار في السكن والمأوى. مستوى دخل الأسرة المادي. عمر الأم حين تتجب الطفل، وكذللك مستواها الثقافي ومستوى الزوج. إن أثر هذه الأسباب على نمو الجنين ونموه فيما بعد يختلف من عائلة إلى مئى أخرى، ومن مجتمع إلى آخر، وكذللك الحال بالنسبة لقدرة الأبوين على التحصيل والإنجاز ، وقدرتهما على البقاء في حالة ساكنة دون حرالك وكذلك قدرتهما على الى التى الإصغاء للآخرين والانتباه إليهم حين يتحدثون أو حين يقرأون. كما يتضح أنه ل لا يوجد اتفاق على الأسباب التي تقف خلف صعوبات التعلم، كما أن مسببات هذه الصعوبات لا تزال غير واضحة، وقد يرجع ذللك إلى كون هذا لهاب المجال حديث أو التشابك بين صعوبات التعلم والتخلف العقلي من جهة وبينها وبين الاضطرابات الانفعالية والسلوكية من جهة أخرى، وقد ترجع هذه الاختلافات حول مل

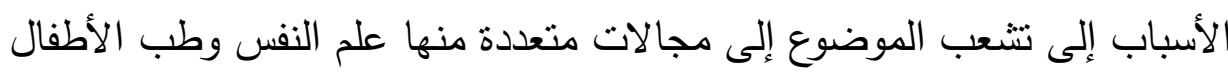


استخدم البحث الاستبيان كأداة، حيث أن الاستبيان من أكثر أدوات البحث

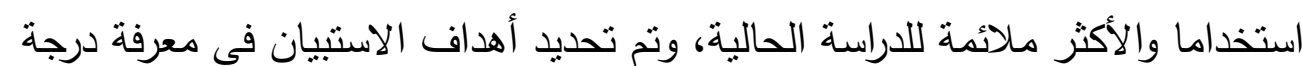
معوقات توظيف تقنيات التعليم التي تواجه معلمي صعوبات التعلم بالمرحلة الابتدائية بمدينة مكة المكرمة، الخاصة بالمعلم والتلميذ والمنهج والإدارة المدرسية .

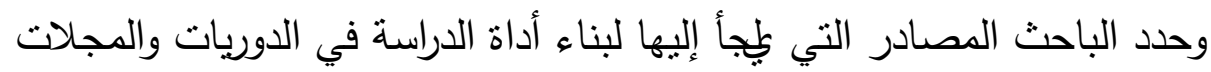
التربوية والبحوث والدراسات السابقة وثيقة الصلة بمشكلة الدراسة الحالية، كما تم مقابلة عدد من ذوو الاختصاص في هذا المجال للاستفادة من خبراتهم.

وقد تم التأكد من الصدق و الثبات على النحو التالي: المات

صدة الأداة : صدق المكمين:

تم عرض الاستبيان في صورته الأولية على مجموعة من المحكمين من ذوي

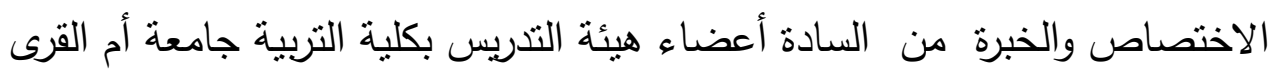

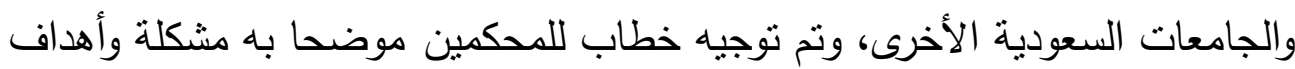
الدراسة وتساؤلاتها، و بلغ عدد المحكمين (15) محكما. وذللك للتأكد من درجة مناسبة الفقرة، ووضوحها، وانتمائها للمحور الذي تتتمي إليه، وسلامة الصياغة اللغوية. وبناءً على آراء المحكمين ومقترحاتهم تم تعديل الأداة . الصددق الإهصاءي: تم التأكد إحصائيا من صدق المقياس بطريقة الاتساق الداخلي، عن طريق حساب معامل الارتباط بين درجة كل فقرة مع المحور الذي تتنمي إليه، وكانت النتائج 
معوقات توظيف تقتيات التعليم التي تواجه معلمي صعويات التعلم بالمملكة العربية السعودية

د.أحمد حلمي محمد أبو المجد - محمد بن امبارك مطلق الشريف معيف

كالتالي: - n

جدول رقم (5 )

معاملات الارتباط بين درجة الفقرة ودرجة المحور

\begin{tabular}{|c|c|c|c|c|c|}
\hline \multicolumn{2}{|c|}{ المحور الثالث } & \multicolumn{2}{|c|}{ المحور الثاني } & \multicolumn{2}{|c|}{ المحور الأول } \\
\hline معامل الارتباط & الفقرة & معامل الارتباط & |لفقرة & معامل الارتباط & الفقرة \\
\hline 0.68 & 1 & 0.69 & 1 & 0.71 & 1 \\
\hline 0.69 & 2 & 0.66 & 2 & 0.70 & 2 \\
\hline 0.68 & 3 & 0.73 & 3 & 0.71 & 3 \\
\hline 0.70 & 4 & 0.70 & 4 & 0.68 & 4 \\
\hline 0.70 & 5 & 0.72 & 5 & 0.69 & 5 \\
\hline 0.66 & 6 & 0.74 & 6 & 0.75 & 6 \\
\hline 0.68 & 7 & 0.68 & 7 & 0.71 & 7 \\
\hline 0.72 & 8 & 0.69 & 8 & 0.70 & 8 \\
\hline 0.75 & 9 & 0.70 & 9 & 0.69 & 9 \\
\hline & & 0.73 & 10 & 0.68 & 10 \\
\hline & & 0.69 & 11 & & \\
\hline & & 0.70 & 12 & & \\
\hline & & 0.73 & 13 & & \\
\hline & & 0.68 & 14 & & \\
\hline
\end{tabular}

تراوحت قيم معاملات الارتباط من ( 0.66) إلى (0.75)، وجميع قيم معاملات

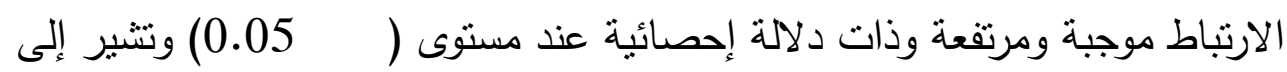

الاتساق الداخلي، بين درجة كل فقرة ودرجة المحور الذي تتنمي إليه.

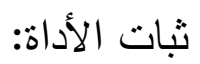


معوقات توظيف تقتيات التعليم التي تواجه معلمي صعويات التعلم بالمملكة العربية السعودية

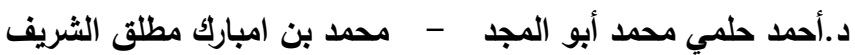

تم التأكد من ثبات الأداة بطريقة معامل الفا كرونباخ، وكانت النتائج كالتالي:

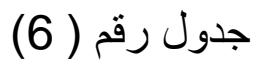

\begin{tabular}{|c|c|}
\hline قيمة الفا كرونباخ & المحور \\
\hline 0.91 & الأول \\
\hline 0.93 & الثاني \\
\hline 0.94 & الثالث \\
\hline
\end{tabular}

تراوحت قيم معامل الفا كرونباخ من (0.90) إلى (0.94) وهي مرتقعة وتثثير إلى أن أداة الدراسة عالية الثبات. الاستبيان في صورنث النهائية:

بعد التأكد من صدق وثبات أداة الدراسة، أصبح الاستبيان في صورته النهائية،

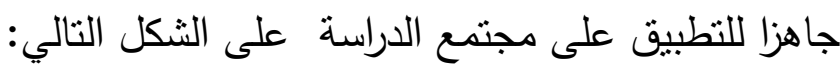
الجزء الأول: المعلومات الشخصية عن مجتمع الدراسة من حيث: (السن - المؤهل العلمي - الخبرة العلمية - الدورات التدريبية ). الجزء الثاني: و يشمل (47) فقرة وزعت على (5) محاور، وكل محور يشمل عدة فقرات كالتالي:

المحور الأول: المعوقات التي تخص معلم صعوبات التعلم، يشتمل على (10) فقرات المحور الثاني: المعوقات التي تخص الإدارة المدرسية، يشتنمل على (14) فقرات المحور الثالث: المعوقات التي تخص المنهج، يشنتل على (9) فقرات

\section{تصميح الاستبانة:}

تعطى الدرجة ( 5) للاستجابة موافق بشدة والدرجة ( 4) للاستجابة موافق

والدرجة ( 3) للاستجابة محايد والدرجة ( 2) للاستجابة غير موافق، والدرجة ( 1) للاستجابة غير موافق بثدة. وفقا للمقياس الخماسي نم استخدام المعيار التالي للحكم 
معوقات توظيف تقتيات التعليم التي تواجه معلمي صعويات التعلم بالمملكة العربية السعودية

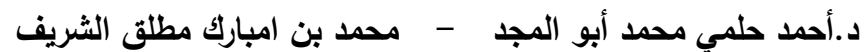

على درجة الموافقة:

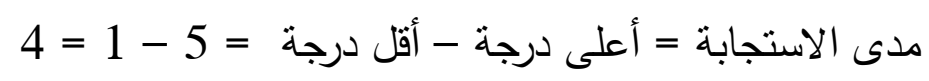

طول الفئة = مدى الاستجابة / عدد فئات الاستجابة = 5/4 = 0.8

\begin{tabular}{|c|c|}
\hline الاستجابة & الفئة \\
\hline غير موافق بشدة & $1.8-1$ \\
\hline غير موافق & $2.6-1.81$ \\
\hline محايد & $3.4-2.61$ \\
\hline موافق & $4.2-3.41$ \\
\hline موافق بشدة & $5-4.21$ \\
\hline
\end{tabular}

الأاساليب الإهصائية:

للإجابة عن تساؤلات الاراسة تم استخدام الأساليب الإحصائية الآتية: 1 r - المتوسط الحسابي ، والانحراف المعياري وذلك لحساب القيمة التي يعطيها أفراد

$$
\text { مجتمع الدراسة لكل فقرة أو مجموعة من الفقرات(المحور) . }
$$

r - احتبار (ت) للمقارنة بين منوسطات استجابات مجتمع الدراسة حسب متغير السن.

ع - احتبار مان وتتي (ي) للمقارنة بين متوسطات استجابات مجتمع الدراسة حسب

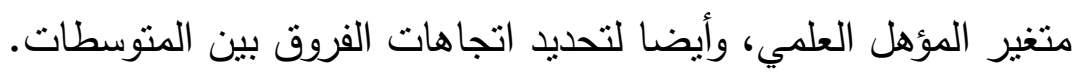

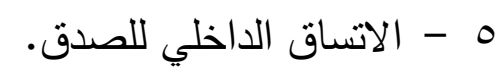
7

\section{نتائج البحث:}

في هذا الفصل نم الإجابة على تساؤلات البحث ، ومن ثم الوصول إلى النتائج وعرضها ومناقتنها والسعي في تفسير تلك النتائج من خلا أدبيات الإطار النظري والدراسات السابقة على النحو التالي: 
معوقات توظيف تقتيات التعليم التي تواجه معلمي صعويات التعلم بالمملكة العربية السعودية

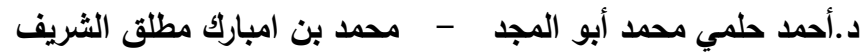

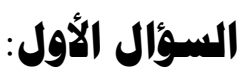

ما معوقات توظيف تقنيات التعليم التي تواجه معلمي صعوبات التعلم بالمرحلة الابتدائية بمدينة مكة المكرمة، الخاصة بالمعلم؟

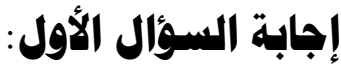

تم استخدام بعض مقاييس الإحصاء الوصفي والتي تمثلت في المتوسط

الحسابي والانحراف المعياري والمتوسط الحسابي العام، للفقرات المدونة في المحور الأول والتي تقبس معوقات توظيف تقنيات التعليم التي تواجه معلمي صعوبات التعلم بالمرحلة الابتدائية بمدينة مكة المكرمة، الخاصة بالمعلم، وكانت النتائج كالتالي:

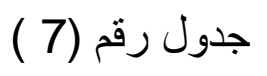

المتوسطات الصسابية والانهرافات المعيارية لاستجابات هجتهم الدراسة حول حول المحور الأول: المعوقات التي تقص معلم صعوبات التعلم

\begin{tabular}{|c|c|c|c|c|c|}
\hline \multicolumn{4}{|c|}{ درجة الموافقة } & \multirow[b]{2}{*}{ 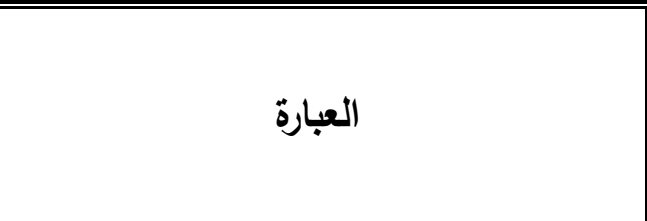 } & \multirow[b]{2}{*}{$\overline{\bar{a}}$} \\
\hline الاستجابة & الانحراف & المستوسطي & 牙: & & \\
\hline موافق & 0.75 & 4.4 & 1 & غياب الدورات تدربيية أثناء الخدمة في & 7 \\
\hline موافق & 0.97 & 4.33 & 2 & $\begin{array}{c}\text { افتقار برامج إعداد المعلم إلى مقررات } \\
\text { ثقنيات التعليم. }\end{array}$ & 8 \\
\hline موافق & 0.71 & 4.19 & 3 & 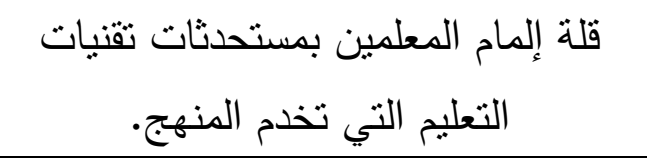 & 6 \\
\hline 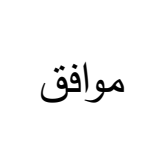 & 0.94 & 4.16 & 4 & ضتعف الحوافز المادية والمعنوية للمعلمين & 5 \\
\hline 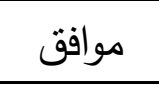 & 1.17 & 3.9 & 5 & غياب خطط التعاون بيني وبين أخصائي & 4 \\
\hline
\end{tabular}


معوقات توظيف تقتيات التعليم التي تواجه معلمي صعويات التعلم بالمملكة العربية السعودية د.أحمد حلمي محمد أبو المجد - محمد بن امبارك مطلق الشريف

\begin{tabular}{|c|c|c|c|c|c|}
\hline \multicolumn{4}{|c|}{ درجة الموافقة } & \multirow[b]{2}{*}{ العبارة } & \multirow[b]{2}{*}{$\overline{\bar{a}}$} \\
\hline الاستجابة & الانعراف المعياري & المستوسطي & 雪 & & \\
\hline & & & & مصادر التعلم لتوظيف تقنيات التعليم. & \\
\hline موافق & 1.41 & 3.86 & 6 & ضعف تأهيلي لاستخدام التقنية التعليمية & 3 \\
\hline موافق & 1.16 & 3.8 & 7 & عدم مناسبة التقنيات التعليمية المتوفرة & 9 \\
\hline موافق & 1.27 & 3.7 & 8 & $\begin{array}{l}\text { ضعف إلمامي بقواعد استخدام التقنيات } \\
\text { التعليمية يقلل من استخدامي لها. }\end{array}$ & 2 \\
\hline موافق & 1.65 & 3.69 & 9 & عدم قناعاتي بأهمية التقنية التعليمية في & 1 \\
\hline موافق & 1.42 & 3.64 & $\begin{array}{l}1 \\
0\end{array}$ & إنهاء المنهدام التقنية التعليمية يعيق عملية & 10 \\
\hline موافق & 0.85 & 3.97 & & المتوسط العام & \\
\hline
\end{tabular}

من نتائج الجدول رقم ( 7 ) يتضح أن المتوسط الحسابي العام لاستجابات مجتمع الدراسة على فقرات المحور الأول (المعوقات التي تخص معلم صعوبات التعلم) يساوي (3.97)، وهو يثير إلى استجابة بدرجة (موافق) على معوقات توظيف تقنيات التعليم التي تواجه معلمي صعوبات التعلم بالمرحلة الابتدائية بمدينة مكة المكرمة، الخاصة

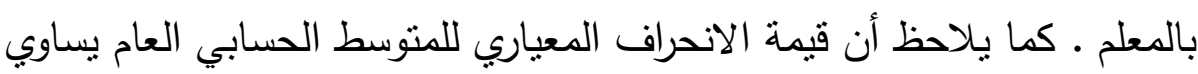

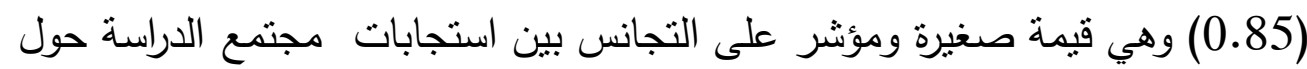
المعوقات التي تخص معلم صعوبات التعلم. كما تتشير نتائج الجدول رقم (7 ) أن معوقات توظيف تقنيات التعليم التي تواجه معلمي صعوبات التعلم بالمرحلة الابتدائية بمدينة مكة المكرمة، الخاصة بالمعلم ، نم 
معوقات توظيف تقتيات التعليم التي تواجه معلمي صعويات التعلم بالمملكة العربية السعودية

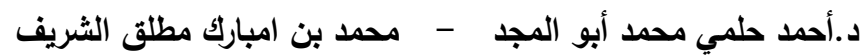

قياسها من خلال ( 10) فقرات، ولوحظ وجود استجابة بدرجة (موافق بشدة) على (2) فقرة، وبدرجة (موافق) على باقي الفقرات (8) فقرات.

تزاوحت قيم المتوسطات الحسابية لدرجات معوقات نوظيف تقنيات التعليم التي تواجه معلمي صعوبات التعلم بالمرحلة الابتدائية بمدينة مكة المكرمة، الخاصة بالمعلم من (3.64) للفقرة رقم (10) وهي (استخدام التقنية التعليمية يعيق عملية إنهاء المنهج الدراسي في وقته المحدد) إلى ( أثناء الخدمة في مجال استخدام التقنية التعليمية في التثريس وهذه المتوسطات الحسابية تقع ضمن الفئة الرابعة (موافق) والفئة الخامسة (موافق بشدة).

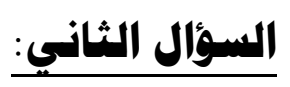

ما معوقات توظيف تقنيات التعليم التي تواجه معلمي صعوبات التعلم بالمرحلة

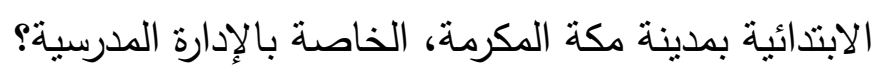

\section{لاجابة السؤال الثاني:}

تم استخدام بعض مقاييس الإحصاء الوصفي والتي تمنلت في المتوسط

الحسابي والانحراف المعياري والمتوسط الحسابي العام، للفقرات المدونة في المحور الثاني والتي تقيس معوقات توظيف تقنيات التعليم التي تواجه معلمي صعوبات التعلم بالمرحلة الابتدائية بمدينة مكة المكرمة، الخاصة بالإدارة المدرسية ، وكانت النتائج كالتالي:

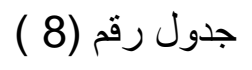

المتوسطات الصسابية والانرافات المعيارية لاستجابات هجتهمع الدراسة حول حول

المحور الثاني: المعوقات التي تخص الإدارة المدرسية المية الماتية

\begin{tabular}{|c|c|c|c|c|c|}
\hline \multicolumn{4}{|c|}{ درجة الموافقة } & \multirow[b]{2}{*}{ العبارة } & \multirow[b]{2}{*}{ 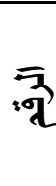 } \\
\hline الاستجابة & 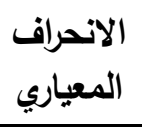 & المستوسط & 得: & & \\
\hline موافق & 0.89 & 4.39 & 1 & عن الأجهزة وجود كتيب إرشادي يوضائل التقنية التعليمية بالمدرسة هوفر & 3 \\
\hline
\end{tabular}


معوقات توظيف تقتيات التعليم التي تواجه معلمي صعويات التعلم بالمملكة العربية السعودية

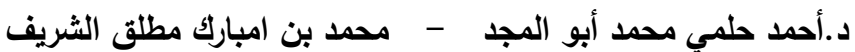

\begin{tabular}{|c|c|c|c|c|c|}
\hline & & & & " المعهد " وكيفية استخدامها. & \\
\hline 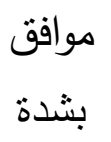 & 0.90 & 4.27 & 2 & صعوبة نقل بعض الأجهزة التقنية إلى الفصول & 14 \\
\hline موافق & 1.25 & 4.14 & 3 & الفصول الدراسية بعيدة عن مركز مصادر & 1 \\
\hline موافق & 1.14 & 4.11 & 4 & 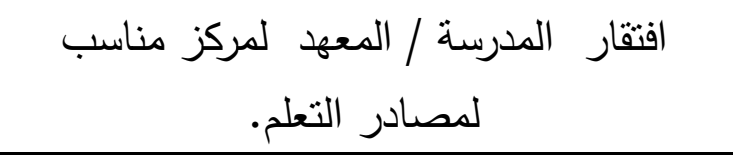 & 5 \\
\hline موافق & 1.09 & 4.09 & 5 & 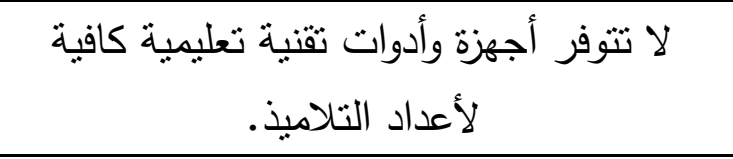 & 13 \\
\hline موافق & 1.09 & 4.07 & 6 & قلة عدد المعلمين القادرين على توظيف تقنيات & 12 \\
\hline موافق & 1.24 & 4.07 & 7 & وقت الحصة غير كاف لاستخدام التقنية & 8 \\
\hline موافق & 0.96 & 4.04 & 8 & الفصول الدراسية غير مهيأة لاستخدام التقنيات & 2 \\
\hline موافق & 1.24 & 3.9 & 9 & عدم وجود تتسيق بين المدرسين لاستخدام & 7 \\
\hline موافق & 1.14 & 3.87 & 10 & عدم مناسبة بعض تقنيات التعليم لفئات تلاميذ & 11 \\
\hline موافق & 1.03 & 3.8 & 11 & كثير من الأجهزة التعليمية المتوفرة غير جيد أو & 4 \\
\hline 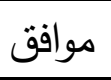 & 1.04 & 3.8 & 12 & ضعف البنية التحتية لمصادر التعلم بالمدرسة. & 9 \\
\hline موافق & 1.28 & 3.7 & 13 & قلة تشجيع مدير المدرسة للمعلمين لتوظيف & 10 \\
\hline 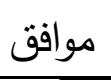 & 1.38 & 3.6 & 14 & لا يوجد معمل لمصادر التعلم بالمدرسة/ المعهد & 6 \\
\hline
\end{tabular}


معوقات توظيف تقتيات التعليم التي تواجه معلمي صعويات التعلم بالمملكة العربية السعودية

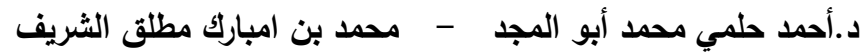

\begin{tabular}{|c|c|c|c|}
\hline & & & - \\
\hline موافق & 0.78 & 4.00 & المتوسط العام \\
\hline
\end{tabular}

من نتائج الجدول رقم ( 8) يتضح أن المتوسط الحسابي العام لاستجاباتمتمع الدراسة على فقرات المحور الثاني (المعوقات التي تخص الإدارة المدرسية ) يساوي (4)، وهو يشير إلى استجابة بدرجة (موافق) على معوقات توظيف تقنيات التعليم التي تواجه معلمي صعوبات التعلم بالمرحلة الابتدائية بمدينة مكة المكرمة، الخاصة بالإدارة المدرسية ـ كما يلاحظ أن قيمة الانحراف المعياري للمتوسط الحسابي العام يساوي (0.78) وهي قيمة صغيرة ومؤشر على التجانس بين استجابات مجتمع الدراسة حول المعوقات التي تخص الإدارة المدرسية. كما تشير نتائج الجدول رقم ( 8) أن معوقات نوظيف تقنيات التعليم التي تواجه معلمي صعوبات التعلم بالمرحلة الابتدائية بمدينة مكة المكرمة، الخاصة بالإدارة المدرسية، نم قياسها من خلال (14) فقرة، ولوحظ وجود استجابة بدرجة (موافق بشدة) على (2) فقرة، وبدرجة (موافق) على باقي الفقرات (12) فقرات. تراوحت قيم المتوسطات الحسابية لدرجات معوقات توظيف تقنيات التعليم التي تواجه معلمي صعوبات التعلم بالمرحلة الابتدائية بمدينة مكة المكرمة، الخاصة بالإدارة المدرسية من (3.6) للفقرة رقم ( 6) وهي (لا يوجد معمل لمصادر التعلم بالمدرسة/ المعهد) إلى ( 4.39) للفقرة رقم ( 3) وهي (عدم وجود كتيب إرشادي يوضح ما هو

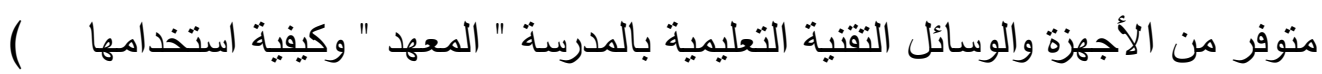
وهذه المتوسطات الحسابية تقع ضمن الفئة الرابعة (موافق) والفئة الخامسة (موافق بشدة).

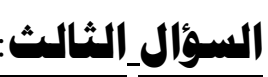

ما معوقات توظيف تقنيات التعليم التي نواجه معلمي صعوبات التعلم بالمرحلة الابتدائية بمدينة مكة المكرمة، الخاصة بالمنهج?

لاجابة السؤال الثالث: 
معوقات توظيف تقتيات التعليم التي تواجه معلمي صعويات التعلم بالمملكة العربية السعودية

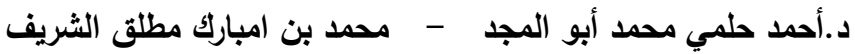

تم استخدام بعض مقاييس الإحصاء الوصفي والتي تمنلت في المتوسط الحسابي والانحراف المعياري والمتوسط الحسابي العام، للفقرات المدونة في المحور الرابع والتي تقيس معوقات توظيف تقنيات التعليم التي تواجه معلمي صعوبات التعلم بالمرحلة الابتدائية بمدينة مكة المكرمة، الخاصة بالمنهج، وكانت النتائج كالتالي: 
معوقات توظيف تقتيات التعليم التي تواجه معلمي صعويات التعلم بالمملكة العربية السعودية د.أحمد حلمي محمد أبو المجد - محمد بن امبارك مطلق الشريف

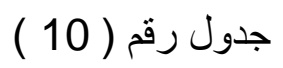

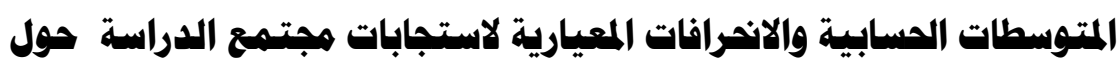

المهور الثالث: المعوقات التي تقص المذهج

\begin{tabular}{|c|c|c|c|c|c|}
\hline \multicolumn{4}{|c|}{ درجة الموافقةة } & \multirow[b]{2}{*}{ العبارة } & \multirow[b]{2}{*}{$\overline{\overline{\mathcal{Z}}}$} \\
\hline الاستجابة & 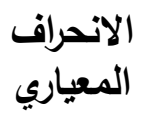 & المستوسط & 得 & & \\
\hline 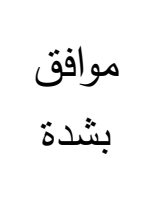 & 0.68 & 4.36 & 1 & 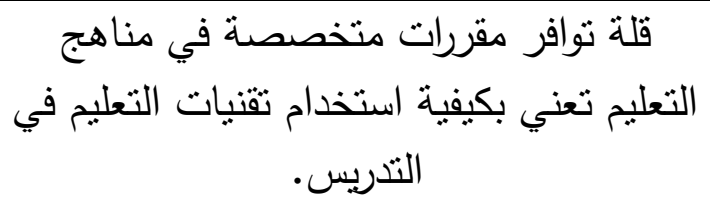 & 9 \\
\hline 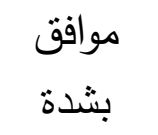 & 0.77 & 4.24 & 2 & قلة الأنشطة التي تدعم استخدام تقنيات التعليم & 7 \\
\hline 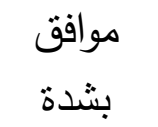 & 0.88 & 4.24 & 3 & ندرة المواقع التعليمية العربية التي تخدم منهج & 3 \\
\hline موافق & 1.10 & 4.2 & 4 & صعوبة توظيف تقنيات التعليم في كثير من التعلم. & 1 \\
\hline موافق & 0.84 & 4.14 & 5 & القصور الثديد في إنتاج البرمجيات العربية & 4 \\
\hline موافق & 0.73 & 4.11 & 6 & عدم توفر دليل لتقنيات التعليم خاص بالمنهج & 8 \\
\hline موافق & 1.04 & 4.07 & 7 & أكبر من تدريس المنهج التقنية التعليمية يحتاج إلى مجهود & 5 \\
\hline موافق & 0.82 & 4 & 8 & تخلو الكتب المقررة من التوجيهات التي تؤكد التعلية وضرورة استخدام التقنيات & 6 \\
\hline موافق & 1.08 & 3.66 & 9 & 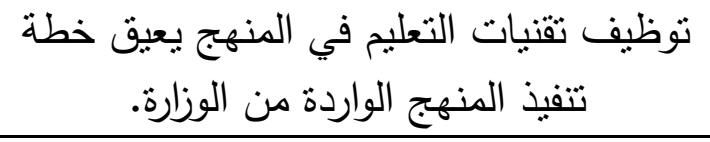 & 2 \\
\hline موافق & 0.56 & 4.11 & & المتوسط العام & \\
\hline
\end{tabular}


من نتائج الجدول رقم ( 10) يتضح أن المتوسط الحسابي العام لاستجاباتجتمع

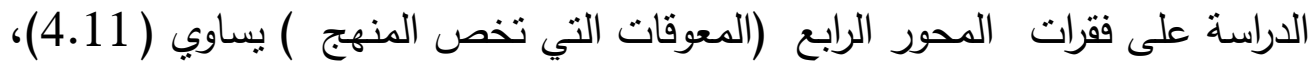
وهو يثير إلى استجابة بدرجة (موافق) على معوقات توظيف تقنيات التعليم التي تواجه

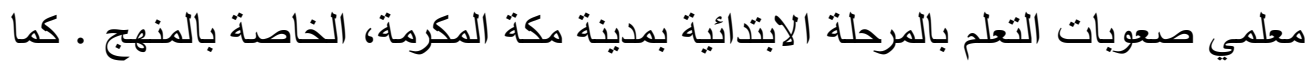
يلاحظ أن قيمة الانحراف المعياري للمتوسط الحسابي العام يساوي ( 0.56) وهي قيمة

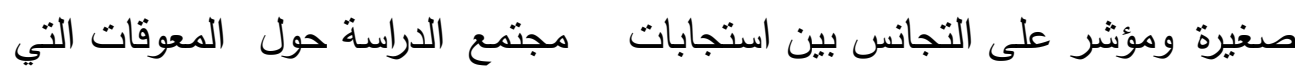
تخص المنهج.

كما تشير نتائج الجدول رقم ( 10) أن معوقات توظيف تقنيات التعليم التي تواجه

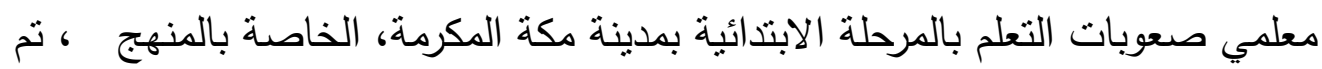
قياسها من خلال ( 9) فقرات ، ولوحظ وجود استجابة بدرجة (موافق بشدة ) على (3) فقرات، وبدرجة (مواقق) على باقي الفقرات (6) فقرات. تراوحت قيم المتوسطات الحسابية لدرجات معوقات توظيف تقنيات التعليم التي تواجه معلمي صعوبات التعلم بالمرحلة الابتدائية بمدينة مكة المكرمة، الخاصة بالمنهج من (3.66) للفقرة رقم (2) وهي (توظيف تقنيات التعليم في المنهج يعيق خطة تتفيذ المنهج الواردة من الوزارة) إلى ( (4.36) للفقرة رقم ( 9 9) وهي (قلة توافر مقررات متخصصة في مناهج التعليم تعني بكيفية استخدام تقنيات التعليم في التدريس ) وهذه المتوسطات الحسابية تقع ضمن الفئة الرابعة (موافق) والفئة الخامسة (موافق بشدة).

إجراء دراسة مشابهة تطبق على المرحلة المتوسطة ومقارنة النتائج مع الدراسة بحوث هقترحة :

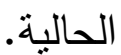

إجراء دراسة مشابهة تطبق على بعض المناطق الأخرى من المملكة ومقارنة النتائج مع الدراسة الحالية. إجراء دراسة مشابهة تطبق على معلمات صعوبات التعلم ومقارنة النتائج مع الدراسة الحالية. 
1 - أبو نيان، إبراهيم سعد(2012م). صعوبات التعلم طرق التدريس والاستراتيجيات

$$
\text { المعرفية. الرياض: دار النشئ النشر الدولي. }
$$

r - أخرس، نائل محمد عبد الرحمن(2005م). مدخل إلى التربية الخاصة. الرياض: مكتبة الرشد.

r - أخضر ، أروى علي عبد الله(2006م)" واقع استخدام الحاسب الآلي ومعوقاته في

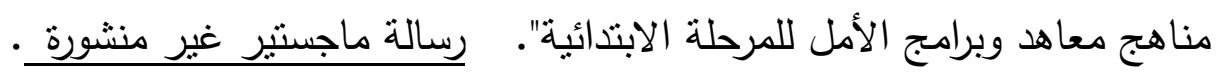
كلية التربية. المناهج وطرق التدريس. جامعة الملك سعود. الرياض. ع - الحازمي، منال عبد الهادي باخت( 1430هـ)" واقع استخدام الحاسب الآلي في مراكز جمعية الأطفال المعوقين لتتمية مهارات الأطفال ذوي الاحتياجات الخاصة من وجهة نظر المديرات والمعلمات". رسالة ماجستير ـ كلية التربية. جامعة أم القرى. مكة المكرمة. ه - الحيلة، محمد محمود(2010م). تكنولوجيا التعليم بين النظرية والتطبيق. عمان:

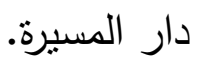
7 - الدعيلج، إبراهيم عبد العزيز (2010م). الاتصال والتقنيات التعليمية. عمان: دار صفاء.

V - الريموني، هيثث يوسف راثد( 2008م). أثز البرامج التذريبية لذوي صعوبات التعلم في الإنجاز الدراسي ومفهوم الذات. عمان: دار الحامد. ᄉ - السعيد، رضا مسعد و الحسيني، هويدا محمد( 2007م). استراتيجيات معاصرة في التدريس للموهوبين والمعوقين. الإسكندرية: مركز الإسكندرية للكتاب. 9 - الصالح، غسان ( 2003م ) الأسباب التى تعزى إليها صعوبات التعلم "دراسة

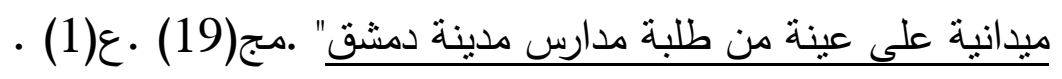

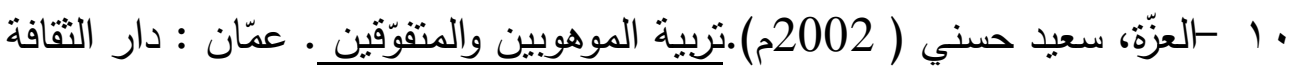
للنشر والتوزيع. 
معوقات توظيف تقتيات التعليم التي تواجه معلمي صعويات التعلم بالمملكة العربية السعودية

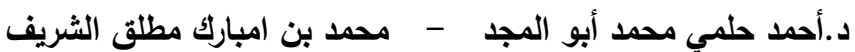

11 أساليب التدريس واستراتيجيات العلاج. عمان: الدار العلمية للنشر . r الغامدي، إسماعيل عبد الرحمن( 2008م)" دور الإنترنت في توظيف الأساليب الإثرافية في العملية التعليمية من وجهة نظر المشرفين التربوبين بمنطقة الباحة". رسالة ماجستير. كلية التربية. جامعة أم القرى. مكة المكرمة. با † الفار، مصطفى محمد(2003م). الدليل إلى صعوبات التعلد. عمان: دار يافا. ع ا ـالفيفي، عيسى أحمد حسين( 1433هـ). واقع استخدام تقنيات التعليم في تدريس القرآن الكريم بالمرحلة الثانوية في مدينة الرياض ومعوقات استخدامها. رسالة ماجستير • كلية العلوم الاجتماعية قسم المناهج وطرق التدريس. جامعة الإمام محمد بن سعود الإسلامية. الرياض.

10 صفاء.

17 تحقيق أهداف برنامج صعوبات التعلم. رسالة ماجستير . كلية التربية. جامعة أم القرى. مكة المكرمة.

IV

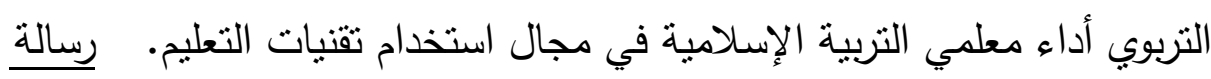
ماجستير. كلية التربية. جامعة أم القرى. مكة المكرمة. 1 1 المغلوث، فهر حمد أحمد(1419هـ). رعاية وتأهيل المعوقين في المملكة العربية السعودية الواقع والطموحات. الرياض: مكتبة الملك فهر الوطنية. 9 1 - حسين، عايدة فاروق (2010م). تكنولوجيا التعليم والاتصال الأسس والمبادئ. الرياض: دار النشر الدولي. • r - خضر ، عبد الباسط منولي( 2005م). التذريس العلاجى لصعوبات التعلم والتأخر الدراسي. القاهرة: دار الكتاب الحديث. 
معوقات توظيف تقتيات التعليم التي تواجه معلمي صعويات التعلم بالمملكة العربية السعودية

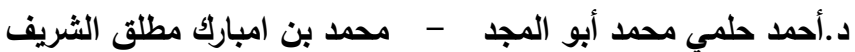

ا Y كراشد، عدنان غائب( 2002م). سيكولوجية الأطفال ذوب الصعوبات التعليمية .

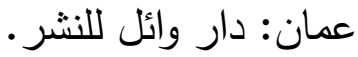

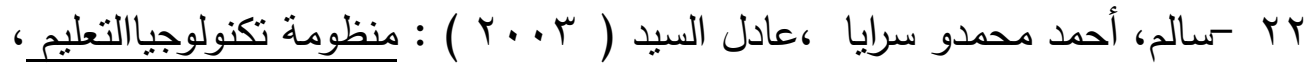
الطبعة الأولى، السعودية : الرياض، مكتبة الرشد.

rr سالم، محمود عوض الله وذكي، أمل عبد المحسن( 2010م). صعوبات التعلد بين النظرية والتطبيق. المنصورة: المكتبة العصرية للنشر •

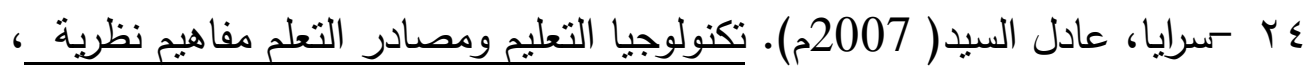
تطبيقات عملية. الرياض: مكتبة الرشد.

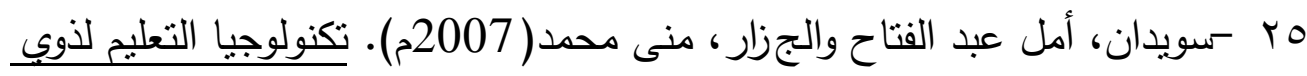
الحاجات الخاصة. عمان: دار الفكر .

Tr -ثمي، نادر سعيد وإسماعيل، سامح سعيد( 2008م). مقدمة في تقنيات التعليم. عمان: دار الفكر.

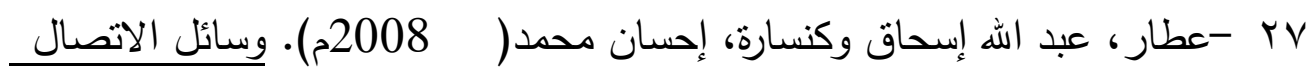
التعليمية. مكة المكرمة: مطبعة بهادر .

个 r -علي، ولاء ربيع وآخرون (2010م). مقدمة إلى التربية الخاصة(سيكولوجية غير العاديين). الرياض: دار النشر الدولي.

و ج -فتح الله، مندور عبد السلام( 2012م). استخدام تكنولوجيا التعليم في التربية الخاصة. الرياض: مكتبة الرشند.

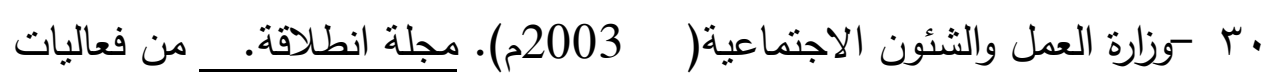

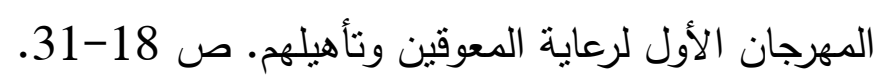

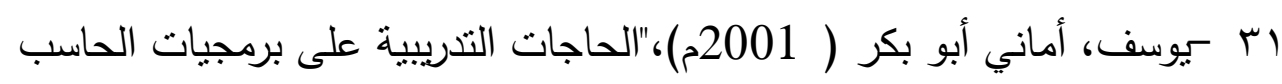

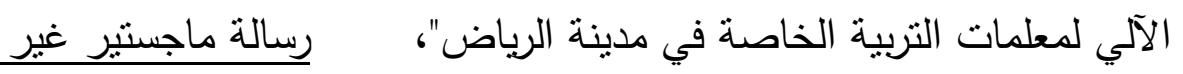
منشورة، قسم الرسائل وتكنولوجيا التعليم، كلية التربية، جامعة الملك سعود. 
معوقات توظيف تقتيات التعليم التي تواجه معلمي صعويات التعلم بالمملكة العربية السعودية

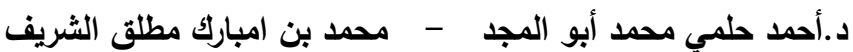

32. Agboola, Isaac \& .Lee, Arthur. (2000). "Computer and Information Technology Access for Deaf Individuals in Developed and Developing Countries". Journal of Deaf Studies and Deaf Education. Vol. No. 3, PP 286-289.

33. Brandt ,D.S.(1997).Constructivism: Teaching for understanding of the internet." Association for computing Machinery Communications of the ACM.40, PP112-117.

34. Council for Exceptional Children (CEC). (2000). What every special educator must know. The standard for the preparation and licensure of special educators (4th ed.). Reston, VA: The Council for Exceptional Children.

35. Hawsawi, A.M. (2002), Teachers Perceptions of Computer Technology Competencies working with students with mild Cognitive Delay . Unpublished Dissertation, University of Idaho. ID, USA.

36. Pillai, Patric. (1999.Dec). "Using Technology To educate Deaf and Hard of Hearing Children in Rural Alaskan General Education Settings" American Annals of the Deaf Journal Citation : vol 144. no5, p373-378. ( EAIC Document Reproduction Service. ED 604 945).

37. Robenson, Len .(2001,Mar). "Integration of Computers and Related Technologies Into Deaf Education Teacher Preparation Programs". America Annals of the Deaf Journal Citation: vol 146. no1, p60-66. (ERIC Document Reproduction Service. ED 62641).

المواقع الإلكترونية:

38. $\quad$ http://www.dahsha.com/old/viewarticle.php?id=27831 